\title{
Special Section Introduction: A Tribute to Frances R. Aparicio
}

\author{
Jillian M. Báez ${ }^{1}$
}

Published online: 23 April 2020

(C) Springer Nature Limited 2020

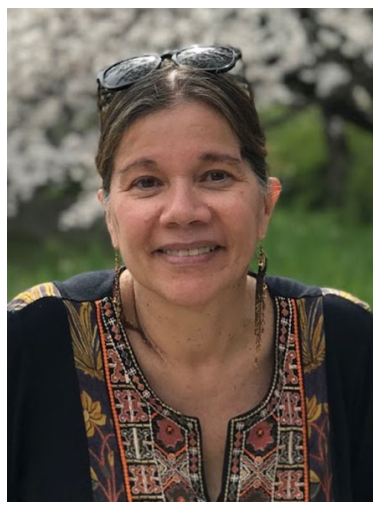

This special tribute section is dedicated to the work of the Latina/o/x studies ${ }^{1}$ pionera Frances R. Aparicio. A dynamic scholar and mentor, Dr. Aparicio ${ }^{2}$ played a central and critical role in the development of Latina/o/x studies as an interdisciplinary field and continues to be a critical steward of Latina/o/x studies as a scholar, teacher, and mentor. In December 2018, Northwestern University hosted the Celebrating the Career of Frances Aparicio Symposium in honor of her service to the profession and in anticipation of her retirement. Frances's colleagues and former students recounted

\footnotetext{
${ }^{1}$ In this essay I toggle between the terms Latina/o studies and Latinx studies, depending on the historical moment and how the specific programs or departments mentioned define themselves. For an in-depth discussion of the current debate on the deployment of "Latinx" in the academy, see de Onis (2017) and Rodriguez (2017).

${ }^{2}$ In this issue we refer to Frances Aparicio as Frances and Dr. Aparicio. Calling Frances by her first name is in alignment with how she operates in the academy. She is known for building horizontal relationships with students and junior colleagues and challenging elitist hierarchies. At the same time, we also wish to give Frances her due respect as a pioneering scholar and leader in the field.
}

\section{Jillian M. Báez}

jb6377@hunter.cuny.edu

1 Hunter College, The City University of New York (CUNY), New York, NY, USA 
stories - many in tears - that spoke to her necessary interventions in the field and how she indelibly shaped the trajectories of their careers. It was clear that Dr. Aparicio made an imprint on countless students across numerous areas of study including language politics, Latinx literature, literary and cultural translation, popular culture, identity, and interdisciplinary approaches in Latina/o studies.

Frances was born in Santurce, Puerto Rico, in 1955. She earned her bachelor's degree at Indiana University-Bloomington in Spanish and comparative literature (1978) and her master's degree and doctorate in Spanish at Harvard University (1983). As a graduate student at Harvard, Dr. Aparicio's course of study centered on Latin American literary translation in the twentieth century. Despite the rigid focus on Spain and Latin America within the discipline of Spanish, Dr. Aparicio maintained an interest in the experiences of Latina/os living in the United States. At Harvard she taught the first "Spanish for U.S. Latinos course" (Aguilar 1999). In addition, as documented in Mérida M. Rúa's essay in this section, Dr. Aparicio served on the guest editorial board as a graduate student for the second issue of the Latina feminist journal Third Woman, dedicated to Latinas on the east coast. As a faculty member, Frances's research would increasingly have a transnational signature attending to issues spanning across the Americas.

Frances's academic career was marked by migration, moving from Puerto Rico to the Midwest, the Northeast, Northern California, the Southwest near the border, and then returning to the Midwest. After Harvard, she served on the faculty of Stanford University, the University of Arizona, the University of Michigan, the University of Illinois at Chicago (UIC), and Northwestern University. Dr. Aparicio's various migrations played a major role in how she developed a comparative and relational approach in Latina/o/x studies, one that pays attention to local as well as transnational linkages. Frances bloomed wherever she was planted, making a lasting impact at each of the institutions where she was appointed. At the University of Michigan, she served as the director of the Latina/o Studies Program in 1992 and from 1994 to 1996. In addition to her administrative work, Frances officially trained a dozen graduate students, and unofficially many more. Several would become leaders in the field, including Dolores Inés Casillas, María Elena Cepeda, Cándida F. Jáquez, Mérida M. Rúa, and Wilson Valentín-Escobar. While at Michigan she also played a pivotal role as a screenwriter and co-producer of the documentary Through My Lens: A Video Project about Women of Color Faculty at the University of Michigan (1999). The short film documents the experiences and challenges of women of color at the University of Michigan, making visible their contributions to the institution, its intellectual community, and beyond, demystifying the numerous difficulties women of color faculty face in a sexist, racist, and classist academy.

From 2000 to 2005, Frances directed the Latin American and Latino Studies Program at the University of Illinois at Chicago (UIC), hiring Marta Ayala as the first community outreach coordinator. Collaborating with Ms. Ayala, a trained organizer, Dr. Aparicio initiated the Lectures in the Community series. The series encompassed not only academic presentations by established Latina/o studies scholars, but also panel discussions, musical performances, poetry and literary readings, and film screenings held in a variety of Latinx settings across the city: community centers, 
neighborhood schools, and local public libraries. From UIC, Frances went on to direct the Latina and Latino Studies Program at Northwestern University, guiding the development and growth of the Latina/o/x studies curriculum and programming.

A prolific and pathbreaking scholar, Dr. Aparicio is perhaps best known for her award-winning monograph Listening to Salsa: Gender, Latin Popular Music, and Puerto Rican Cultures (1998). A groundbreaking book in cultural studies, popular music, literary studies, gender and women's studies, and Latina/o studies, Listening to Salsa won both the Modern Languages Association's Katherine Singer Kovacs Prize for best book in Hispanic literature and the International Association for the Study of Popular Music's Book Award. She edited several anthologies, among them, The Companion to Latino/a Literature (2012) with Suzanne Bost; Musical Migrations: Transnationalism and Cultural Hybridity in Latin/o America (2003) with Cándida F. Jáquez and María Elena Cepeda; and Tropicalizations: Transcultural Representations of Latinidad (1997) with Susana Chavez-Silverman. Taken together, this body of work offers sophisticated analyses of Latina/o cultural production in terms of both subjectification and agency. In writing about Latina/o lived experience, Frances interrogated how Latina/os are policed in terms of both their English- and Spanish-language politics (Aparicio 1995) and coined the term "tropicalization" to explain how Latina/os are Othered, or marked as different (Aparicio and Chávez-Silverman 1997). Her latest book, Negotiating Latinidad: Intralatina/o Lives in Chicago (2019) was born out of her lived experiences with students in Chicago classrooms and raising her Mexi-Rican children. The book explores how Latinidad is lived among Latina/os of multiple Latinx national-origin backgrounds and presents a new paradigm for the field of Latina/o studies that moves beyond comparative studies. All of Frances's writing on Latina/os is emblematic of her intellectual commitment to producing knowledge that reflects and responds to the needs of Latina/o/x communities.

Dr. Aparicio also has made significant inroads and paved new avenues for disseminating research in Latina/o studies. One of the most important ways to ensure that a field will thrive and gain legitimacy in the academy is to create places for scholars to publish their work. Frances was one of the founders of this journal, which released its first issue in 2003. She was responsible for writing a proposal to Palgrave for them to produce the journal, and Frances also hired Suzanne Oboler to serve as the first editor of Latino Studies. Frances also assisted in securing funding for a staff assistant and for Dr. Oboler to travel to conferences to identify potential articles and authors. Dr. Aparicio was also the founding editor of the Latinos in Chicago and the Midwest series, out of the University of Illinois Press, and continues to serve on the editorial board. Dr. Aparicio played a major role in the establishment of the Latina/o Studies Association (LSA). LSA was a collaborative effort launched after conversations with numerous colleagues across the country for several years. During a Latin American Studies Association meeting, Frances and colleagues finally convened the small group that began the work of organizing. This group spent two years consulting with colleagues at various disciplinary conferences and then wrote a document outlining the structure. Frances was a member of the planning committee for the foundational conference in 2014 in Chicago. Today LSA is a full-fledged professional organization 
convening thousands of scholars every other year. In these endeavors, Dr. Aparicio was especially committed to supporting the work of graduate students and junior faculty and, in doing so, investing in the future generations of the field.

Frances built the field of Latina/o studies in a multitude of ways that integrate her leadership, research, teaching, and mentorship. In particular, Dr. Aparicio advocated for interdisciplinary approaches in both her research and training of students, often combining methodologies from the humanities and social sciences. In addition to her contributions to Latina/o/x studies, Frances also pushed other fields, such as Spanish, women's and gender studies, and cultural studies, among others, to deploy unconventional theoretical and methodological approaches in a sustained effort to foreground the experiences of Latinx communities. In doing so, Dr. Aparicio's reach spanned across the academy and deeply influenced how we research Latinx issues today.

Perhaps Frances's most important legacy is the students she mentored. Dr. Aparicio mentored her students in nontraditional ways. For example, Frances would openly offer guidance on how to navigate work-life balance. I particularly benefited from her consejos as a mother-scholar on the tenure-track. She also was very forthcoming about the challenges scholars of color, especially women, face in navigating hierarchies both within and outside of ethnic studies. These challenges included publishing unconventional, interdisciplinary scholarship alongside larger issues of maintaining one's dignity and integrity within hostile institutions. As a mentor, Dr. Aparicio fostered within her students a commitment to bridge academic work with social change. In this special tribute section, several of Frances's mentees reflect on her contributions to the field from various vantage points. Mérida M. Rúa's essay explores how Frances taught her students that there are heterogeneous ways of studying latinidad through engaging competing scholarly paradigms, approaches, and orientations "together, and in conflict with each other." Aaron Aguilar-Ramirez's builds on this approach, deploying Frances's concept of horizontal hierarchies to underscore the hierarches at play within and across Latina/o/x communities in Bencastro's novel Odyssey to the North. My essay focuses on Frances's unsung contributions to cultural studies and media studies, noting how her groundbreaking work shaped our understanding of Latina/o/x representation and reception and re-centered Latinas as cultural readers. Lillian Gorman's piece highlights Dr. Aparicio's careful attention to language politics from both methodological and pedagogical perspectives. Lastly, we include a letter Wilson Valentín-Escobar read at the Northwestern symposium in December 2018. Valentín-Escobar's letter highlights the extraordinary mentorship Frances provided for so many students, labor that often goes unrecognized. Each of these essays are testimonios that bear witness to the myriad ways Frances shaped countless lives both within and outside the academy.

Acknowledgements Thank you to Mérida M. Rúa and the Latino Studies editorial board for their feedback on earlier versions of this introduction. 


\section{References}

Aguilar, J.U.Z. 1999. Entrevista a Frances Aparicio sobre estudios culturales latinos (Interview with Frances Aparicio on Latino Cultural Studies). Ciberayllu 9 (3): 1.

Aparicio, F.R. 1995. Language, Culture, and Violence in the Education Crisis of U.S. Latino/as: Two Courses for Intervention. Michigan Journal of Community Service Learning 2: 95-104.

Aparicio, F.R. 1998. Listening to Salsa: Gender, Latin Popular Music, and Puerto Rican Cultures. Hanover, NH: University Press of New England.

Aparicio, F.R. 2019. Negotiating Latinidad: Intralatina/o Lives in Chicago. Urbana: University of Illinois Press.

Aparicio, F.R., and S. Chávez-Silverman (eds.). 1997. Tropicalizations: Transcultural Representations of Latinidad. Hanover, NH: University Press of New England.

Aparicio, F.R., K. Chandler, and G. Thomas. 1999. Through My Lens: A Video Project About Women of Color Faculty at the University of Michigan. Ann Arbor, MI: Center for the Education of Women, BMC Media Services, University of Michigan, VHS.

de Onis, C.M. 2017. What's in an "X"?: An Exchange about the Politics of "Latinx". Chiricú Latina/o Literatures, Arts, and Cultures 1 (2): 78-91.

Rodríguez, R.T. 2017. X Marks the Spot. Cultural Dynamics 29 (3): 202-213.

Publisher's Note Springer Nature remains neutral with regard to jurisdictional claims in published maps and institutional affiliations. 